\title{
Théologiques
}

Théologiques

\section{Esprits ou esprit?}

\section{Jean-Claude Petit}

Volume 2, numéro 2, octobre 1994

L'esprit

URI : https://id.erudit.org/iderudit/602403ar

DOI : https://doi.org/10.7202/602403ar

Aller au sommaire du numéro

Éditeur(s)

Faculté de théologie de l'Université de Montréal

ISSN

1188-7109 (imprimé)

1492-1413 (numérique)

Découvrir la revue

Citer ce document

Petit, J.-C. (1994). Esprits ou esprit? Théologiques, 2(2), 5-6.

https://doi.org/10.7202/602403ar d'utilisation que vous pouvez consulter en ligne.

https://apropos.erudit.org/fr/usagers/politique-dutilisation/ 
LIMINAIRE

\title{
Esprits ou esprit?
}

\author{
Jean-Claude PETIT \\ Faculté de théologie \\ Université de Montréal
}

La thématique de l'«esprit" traverse toute l'histoire de la pensée occidentale. La théologie chrétienne parle volontiers de l'«esprit» mais elle est loin d'en avoir le monopole. La philosophie parle aussi de l'« esprit ». À notre époque, le développement fulgurant des disciplines issues de la psychologie a accrédité un nouveau discours sur l' "esprit» qui semble avoir pris le relais d'autres traditions de pensée qui avaient aussi fait de celui-ci leur préoccupation. L'histoire des religions et des spiritualités nous rappelle que l'«esprit» a des figures multiformes et qu'il n'est pas du tout l'affaire d'une seule tradition.

L'usage de la langue, qui en chacun de ces cas parle de l'«esprit» au singulier, pourrait accréditer l'idée que tous ces discours, par-delà leur diversité, visent au fond la même chose et qu'il s'agirait finalement pour nous d'identifier celui qui en parle le mieux. Le singulier du titre de ce cahier paraît entériner cet état de chose. Les observations que proposent cependant les textes réunis ici voudraient plutôt convaincre que l'usage langagier familier voile une réalité très diversifiée et que c'est probablement au prix d'une dangereuse simplification et sans doute aussi grâce à un profond oubli des expériences originaires qu'en la plupart de nos langues modernes le même vocable d' «esprit * en est venu à signifier des réalités aussi différentes que la subtilité de l'intelligence, le caractère insaisissable d'un étant corporel, un vivant immatériel, l'être luimême, ou même encore l'essence de la divinité. Reconnaissons tout de même que le pluriel «les esprits » n'aurait pas moins porté à confusion! Aurait-il d'ailleurs été plus approprié ?

Les discours sur l' "esprit» connaissent à notre époque un regain d'intérêt. Plusieurs se déploient avec l'assurance de savoir clairement ce qu'il en est de l' "esprit" dont la tradition johannique disait pourtant que «nul ne sait où il va ni d'où il vient, mais qu'il souffle où il veut". D'autres 
se construisent à partir d'emprunts non critiqués à toutes sortes de traditions, comme s'il était clair que derrière le même mot se cachait la même chose. Sans doute conviendrait-il d'être plus hésitant!

Par delà les apparences d'une banale juxtaposition, les textes qui suivent voudraient prendre le risque d'un nouveau dialogue. Articulés à partir d'horizons fort différents de l'un à l'autre, les observations ou les mises au point qu'ils proposent pourraient nous aider à mieux poser une question que nos discours tiennent le plus souvent pour résolue: que voulons-nous dire au juste quand nous parlons de l'kesprit " ? 